\title{
Mandarin and English Single Word Processing Studied with Functional Magnetic Resonance Imaging
}

\author{
Michael W. L. Chee, ${ }^{1}$ Edsel W. L. Tan, ${ }^{1}$ and Thorsten Thiel ${ }^{2}$ \\ ${ }^{1}$ Cognitive Neuroscience Laboratory, Singapore General Hospital, Singapore 169856, Singapore, and 2MR-Tomography, \\ Department of Radiology, University of Freiburg, Freiburg 79104, Germany
}

\begin{abstract}
The cortical organization of language in bilinguals remains disputed. We studied 24 right-handed fluent bilinguals: 15 exposed to both Mandarin and English before the age of 6 years; and nine exposed to Mandarin in early childhood but English only after the age of 12 years. Blood oxygen level-dependent contrast functional magnetic resonance imaging was performed while subjects performed cued word generation in each language. Fixation was the control task. In both languages, activations were present in the prefrontal, temporal, and parietal regions, and the supplementary motor area. Activations in the prefrontal region were compared by (1) locating peak activations and (2) counting the number of voxels that exceeded a
\end{abstract}

statistical threshold. Although there were differences in the magnitude of activation between the pair of languages, no subject showed significant differences in peak-location or hemispheric asymmetry of activations in the prefrontal language areas. Early and late bilinguals showed a similar pattern of overlapping activations. There are no significant differences in the cortical areas activated for both Mandarin and English at the single word level, irrespective of age of acquisition of either language.

Key words: bilingualism; functional magnetic resonance imaging; brain mapping; English-Chinese comparison; visual word processing; language
The cerebral organization of bilinguals with respect to language is still disputed, despite many investigations with different modalities. We sought to clarify our understanding of cerebral areas involved in single word processing in different languages by asking two questions. Does the processing of Mandarin, an ideographic script, activate brain areas that are distinct from those activated by English, an alphabetic script? Does early versus later acquisition of a second language affect the functional anatomy of language processing?

A case for interhemispheric differences in localization for first (L1) and second (L2) languages is based on reports of the differential language deficits observed in a minority of patients with stroke (Albert and Obler, 1978; Paradis, 1995) and a functional magnetic resonance imaging (fMRI) study (Dehaene et al., 1997). Intrahemisphere differences in where L1 and L2 are processed are suggested by electrical stimulation (Ojemann and Whitaker, 1978) and functional neuroimaging (Kim et al., 1997; Perani et al., 1996).

That most bilingual or polyglot patients with stroke sustain equal deficits in all languages, however, suggests common or significant overlap in the cortical organization of L1 and L2. This is supported by a pair of positron emission tomography experiments using single word tasks (Klein et al., 1994, 1995). Common areas within the left frontal region were activated in within- and across-language lexical searches in French and English (Klein et al., 1995).

Do some languages have special processing requirements? Pro-

Received Sept. 8, 1998; revised Jan. 21, 1999; accepted Jan. 26, 1999.

This work was supported by National Medical Research Council of Singapore Grant NMRC 98/00270. Dr. Susan Liow and Olivia Wee created the behavioral stimuli and helped recruit subjects. Fock Siu Ling, Soon Chun Siong, and Hoon Jia Jia helped edit this manuscript.

Correspondence should be addressed to Michael W. L. Chee, Singapore Gamma Knife Centre, 20 College Road, Singapore 169856, Singapore.

Copyright (C) 1999 Society for Neuroscience $0270-6474 / 99 / 193050-07 \$ 05.00 / 0$ cessing of American Sign Language was associated with right hemisphere activations, in addition to classical left hemisphere activations (Neville et al., 1998). English, in contrast, did not produce right hemisphere activations, and the authors suggested that the additional activations were attributable to the temporal coincidence of language information and visuospatial decoding. Because Mandarin has an ideographic script requiring one to memorize the phonology and meaning of each character to vocalize and comprehend, it may be expected to require processing resources distinct from English.

Sentence processing is more complex than single word processing. Intrahemispheric and interhemispheric differences in activation between L1 and L2 in sentence level studies that are not observed with single word studies may be partly a result of differences in syntactic processing. Because words are the building blocks of sentences, it is preferable to probe for languagespecific processing requirements at single word level before seeking these at the sentence level.

We also studied the cortical organization of L1 and L2 as a function of when L2 was acquired. Several lines of evidence suggest that the early acquisition of language produces better linguistic competency and that the organization of L2 may be affected by age of acquisition (Harley and Wang, 1997). We reexamined the issue of a change in cerebral plasticity with regard to language acquisition by comparing subjects who were naive to English before the age of 12 years with a group who were English-Mandarin bilingual before the age of 6 years.

\section{MATERIALS AND METHODS}

Subjects. A total of 24 healthy right-handed subjects who were bilingual in English and Chinese participated in this study. (Mandarin is the dialect of Chinese we used in this study. The written form of the Chinese language is the same for all dialects, but the spoken form is different for each dialect. The word "Chinese" is used when reference to dialects other than Mandarin may be involved.) Subjects were recruited on a voluntary basis and gave written, informed consent. 
Each subject completed a language background questionnaire and a modified handedness questionnaire. All subjects use English and Mandarin daily. Singaporean subjects scored at least a "B" grade in both languages at the middle and high school levels. Before the experiments, subjects were tested on a set of stimuli similar to those used during the experiment.

Fifteen early bilinguals (EB) were exposed to both English and Chinese in spoken, as well as written, form by the age of 6 years. These comprised individuals who were exposed to English before Chinese or vice versa and were ethnic Chinese born and raised in Singapore. Although 11 of these subjects listed Mandarin as L1, 13 presently use English most frequently. Nine late bilinguals (LB) comprised persons from the People's Republic of China whose first exposure to English occurred at or after the age of 12 years. Until they lived in Singapore, these late bilinguals had their English language skills heavily biased toward reading and writing, in contrast to listening and speaking. Indeed, for most of these subjects, writing skills in English still remain superior to speaking and listening skills. English aside, another concern was that although Mandarin has a common orthography, the phonology of Chinese from different regions in China is different. Further, the intonation of Mandarin and English by our two subject pools is different. There is evidence that segmentation of speech sounds occurs according to templates built during initial exposure to spoken words (Kuhl, 1994). The fitting of unfamiliar pronunciation to such templates to comprehend "foreign" accents may unwittingly add to processing load. Our use of visual word tasks sought to circumvent these confounds.

Apparatus and scanning procedure. Scanning was performed in a $2.0 \mathrm{~T}$ Bruker Tomikon S200 system (Bruker, Kalsruhe, Germany). A gradientecho EPI sequence with the following parameters was used: effective echo time, $40 \mathrm{msec}$; repetition time, $2000 \mathrm{msec}$; field of view, $22 \times 22 \mathrm{~cm}$ or $23 \times 23 \mathrm{~cm}$ depending on subject head size; a $128 \times 64$ pixel matrix (128 pixels in the anteroposterior direction); 17 contiguous oblique axial slices 4-mm-thick (skip $2 \mathrm{~mm}$ ). Six hundred images were collected at each of the slice locations in six separate imaging runs. High-resolution T1weighted anatomical reference images were obtained as a set of 128 contiguous axial slices using a three-dimensional spoiled gradient-echo sequence. Head motion was reduced using a "bite bar" system (Institute of Materials Research Engineering, Singapore).

Stimuli and activation tasks. Word stimuli were presented through a fiber-optic projector system (Avotec, Jensen Beach, FL). Mandarin and English words were presented as text items using Chinese Language Kit (Apple Computer, Cupertino, CA) and MacStim (Dave Darby, Melbourne, Australia) software. There were two variations of the word task.

In experiment set 1 , nine EB subjects silently completed word stems (for example, "cou" for "couple") (Buckner et al., 1995) when they were presented English word stems and to complete a compound word in Mandarin (Fig. 1). Word stems or single Mandarin characters were displayed for $1 \mathrm{sec}$, followed by fixation for $1 \mathrm{sec}$. Blocks of 15 stimuli were separated by $20 \mathrm{sec}$ of fixation on a small cross. Each "run" comprised two blocks of Mandarin words, two blocks of English stimuli, and four blocks of fixation. Presentation of English (E) and Mandarin (M) stimuli was counterbalanced (MEME and EMEM), and six runs of stimuli were performed by each subject.

In experiment set 2 comprising six EB and nine LB subjects, the block design was identical to set 1 . Word stimuli were exposed for $1.5 \mathrm{sec}$ instead of $1 \mathrm{sec}$. The total time between successive stimulus presentations remained $2 \mathrm{sec}$. English word stems were to be completed from the left only, e.g., "— ter," could be completed by making the word "water." Mandarin partial characters containing a right-hand radical were presented, and the subject filled in the left-hand radical.

The first task design paralleled that used in previous studies in English because we wanted to see whether our results would concur with activations reported in previous studies (Buckner et al., 1995; Ojemann et al., 1998). Although the compound two-character Mandarin word generated represents a single concept, it may be criticized as not being a true single word task. The second task also requires lexical access but allows for a closer between-language comparison. Both of these tasks are not perfectly matched linguistically. However, compared with verb generation in which "code switching" can occur, cued word generation constrains one to think in the desired language.

Image processing and data analysis. Images were processed using MedX 2.11 (Sensor Systems, Bethesda, MD) after a phase correction to minimize Nyquist ghosts. fMRI images were motion corrected using Automated Image Registration (AIR) (Woods et al., 1992). To reduce the effect of variation of MR signal between runs, the resulting motion-

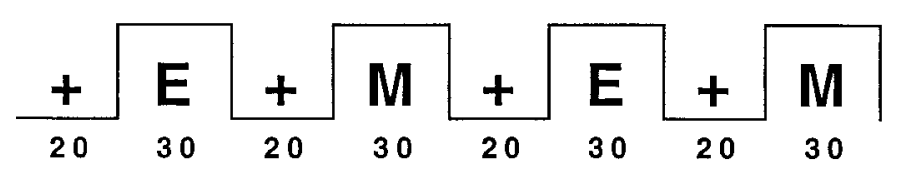

Stimulus

Response

Experiment set 1

English

Mandarin

cou

couple

Experiment set 2

$\begin{array}{lll}\text { English } & \text { est } & \text { crest } \\ \text { Mandarin } & \text { 可 } & \text { 诃 }\end{array}$

Figure 1. The top shows the block timing of stimulus presentation. E, English; $M$, Mandarin. Stimuli were presented every $2 \mathrm{sec}$. The exposure duration was $1 \mathrm{sec}$ in experiment set 1 and $1.5 \mathrm{sec}$ in set 2 . The bottom shows exemplars of the stimuli and possible responses.

corrected images were globally normalized to an empirically determined median value of 6500 units.

Skull stripping of anatomical images was performed with a semiautomated segmentation utility. These images were then transformed into Talairach space using a linear scaling method, and the transformation matrix was saved. The first time point of the normalized motioncorrected images was then registered to the high-resolution skullstripped anatomical image using AIR. The transformation matrix for this procedure was saved.

Functional images were grouped into English, Mandarin, and fixation groups. Images were shifted $4 \mathrm{sec}$ to allow for a time lag in the rise of blood oxygen level-dependent signal after presentation of word stimuli. Unpaired $t$ tests were then applied to the groups of images. Three comparisons using a boxcar function to model subject response were made: English versus fixation, Mandarin versus fixation, and English versus Mandarin. A Z-score threshold of 5 was used to generate activation maps. Activated voxels in regions of interest were checked to see whether there was an appropriate time-locked variation in MR signal in relation to stimulus presentation.

Z-score maps were transformed into Talairach space and fused to the high-resolution anatomical images. Voxels showing peak statistical values were detected, and these were compared across the two languages. Images were then imported into Photoshop (Adobe Systems, San Jose, $\mathrm{CA}$ ) in which a rectangular image mask in the frontal regions covering slices from $\mathrm{Z}$ values of $12-34 \mathrm{~mm}$ was placed in an overlying layer. Voxels exceeding a statistical threshold of a $Z$ value of 5 and that were within the bounds of this mask in the lateral frontal regions were counted. An asymmetry index (AI) of activated voxels was calculated for each language (Binder et al., 1996). Correlation was computed for English and Mandarin asymmetry indices in EB and LB groups using Statview 4.5 (Abacus Concepts, Berkeley, CA). Despite the potential for engaging different cognitive components, inspection of the activation maps obtained from EB subjects showed a similar pattern of activation in the two experimental tasks, except that set 2 resulted in less temporal activation. Given this and our primary focus on intrasubject consistency in language organization, we pooled data from experiment sets 1 and 2 in computation of correlation.

\section{RESULTS}

The pattern of brain activations seen in response to Mandarin words was strikingly similar to that seen for English words (Tables 1,2 ). This was true of $\mathrm{EB}$, as well as $\mathrm{LB}$, subjects (Fig. $2 A, B$ ).

Activations of the prefrontal region involving the rostral middle 


\section{Table 1. Summary of English and Mandarin subjects}

\begin{tabular}{|c|c|c|c|c|c|c|c|c|}
\hline \multirow[b]{2}{*}{ Subject } & \multirow[b]{2}{*}{ L1 } & \multirow{2}{*}{$\begin{array}{l}\text { Age exposed } \\
\text { to L2 in } \\
\text { years }\end{array}$} & \multicolumn{2}{|c|}{$\begin{array}{l}\text { Peak location in Talairach } \\
\text { coordinates (left frontal) }\end{array}$} & \multicolumn{2}{|c|}{ Voxel count: left frontal } & \multicolumn{2}{|c|}{ Voxel count: right frontal } \\
\hline & & & Mandarin & English & Mandarin & English & Mandarin & English \\
\hline Early bilinguals & & & $(x, y, z ; \mathrm{mm})$ & $(x, y, z ; \mathrm{mm})$ & & & & \\
\hline \multicolumn{9}{|l|}{ Males } \\
\hline TI (1) & Mandarin & 5 & $-36,10,28$ & $-36,10,28$ & 263 & 463 & 228 & 293 \\
\hline LE (1) & English & 5 & $-42,6,24$ & $-42,6,24$ & 441 & 603 & 16 & 36 \\
\hline LI (1) & Mandarin & 5 & $-42,4,26$ & $-44,4,26$ & 449 & 147 & 15 & 13 \\
\hline $\mathrm{BA}(1)$ & English & 4 & $-42,22,22$ & $-42,22,22$ & 545 & 824 & 137 & 352 \\
\hline RE (2) & English & 2 & $-38,14,22$ & $-38,12,22$ & 319 & 343 & 71 & 77 \\
\hline YE (2) & English & 5 & $-38,16,32$ & $-38,16,32$ & 595 & 463 & 93 & 93 \\
\hline LO (2) & Mandarin & 5 & $-34,10,24$ & $-34,10,24$ & 695 & 659 & 54 & 16 \\
\hline \multicolumn{9}{|l|}{ Females } \\
\hline EL (1) & Mandarin & 6 & $-32,24,12$ & $-32,24,12$ & 147 & 274 & 0 & 8 \\
\hline LN (1) & Mandarin & 5 & $-32,4,30$ & $-32,4,30$ & 239 & 769 & 16 & 131 \\
\hline LA (1) & Mandarin & 6 & $-34,8,18$ & $-34,8,18$ & 219 & 443 & 18 & 101 \\
\hline SI (1) & Mandarin & 4 & $-34,22,14$ & $-34,22,14$ & 236 & 48 & 27 & 0 \\
\hline SO (1) & Mandarin & 5 & $-40,16,34$ & $-38,16,34$ & 554 & 430 & 176 & 183 \\
\hline ME (2) & Mandarin & 5 & $-38,10,34$ & $-38,10,34$ & 128 & 127 & 143 & 106 \\
\hline SK (2) & Mandarin & 4 & $-40,24,14$ & $-40,24,14$ & 541 & 673 & 64 & 143 \\
\hline JA (2) & Mandarin & 6 & $-44,16,24$ & $-44,18,24$ & 527 & 512 & 263 & 297 \\
\hline \multicolumn{9}{|l|}{ Late bilinguals } \\
\hline \multicolumn{9}{|l|}{ Male } \\
\hline LZ (2) & Mandarin & 13 & $-28,16,34$ & $-28,16,34$ & 176 & 286 & 124 & 131 \\
\hline \multicolumn{9}{|l|}{ Females } \\
\hline HU (2) & Mandarin & 15 & $-30,18,26$ & $-30,18,26$ & 290 & 391 & 97 & 129 \\
\hline YA (2) & Mandarin & 15 & $-38,24,20$ & $-38,28,18$ & 413 & 287 & 22 & 39 \\
\hline JI (2) & Mandarin & 13 & $-26,12,28$ & $-26,12,28$ & 200 & 178 & 33 & 49 \\
\hline GU (2) & Mandarin & 20 & $-34,10,40$ & $-34,10,40$ & 469 & 484 & 146 & 128 \\
\hline $\mathrm{ZH}(2)$ & Mandarin & 15 & $-40,8,20$ & $-40,8,20$ & 541 & 522 & 249 & 317 \\
\hline $\mathrm{ZN}(2)$ & Mandarin & 12 & $-34,4,32$ & $-34,4,32$ & 265 & 258 & 170 & 182 \\
\hline JU (2) & Mandarin & 17 & $-30,18,20$ & $-28,18,20$ & 337 & 316 & 136 & 129 \\
\hline DA (2) & Mandarin & 12 & $-38,12,28$ & $-38,12,28$ & 334 & 361 & 14 & 8 \\
\hline
\end{tabular}

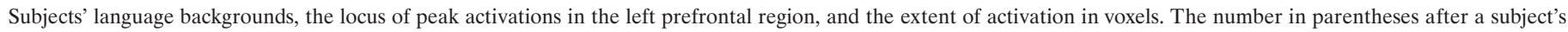
initials indicates the experimental protocol used: 1 , experiment set $1 ; 2$, experiment set 2 .

and inferior frontal gyri [Brodmann's area (BA) 44/45, 46/9], the supplementary motor area, and bilateral occipital and bilateral parietal regions (BA 7) were similar to those reported previously (Buckner et al., 1995; Ojemann et al., 1998), although the word task was somewhat different. Temporal activations were seen in some subjects (Fig. 3). Five subjects showed modest activations in the posterior temporal region (BA 22/21). In addition, two subjects showed activations in the anterior temporal pole (BA 38). Basal temporal area (BA 37) activations in region of the posterior fusiform gyrus were observed in 10 subjects.

The location of peak activations in both languages within the left prefrontal region coincided completely in 20 of 24 subjects, and in the remaining four subjects, the interpeak distances were always $<4.5 \mathrm{~mm}$ (Table 1 ). Of the latter four subjects, two were EB and two were LB. The plot of the AI for Mandarin against that for English showed a good correlation between the two variables within subjects. This was true of EB (Pearson correlation coefficient, 0.91) and LB (Pearson correlation coefficient, 0.91 ) groups (Fig. $4 A, B$ ). These data suggest that any asymmetry of brain activations during word generation was similar for both languages.

When they occurred, temporal activations showed an overlap in the activation maps, but we did not analyze these in detail because not all subjects showed activation in these regions.

Although the correspondence between English and Mandarin activations was significant in all subjects, in some, the number of pixels activated above threshold in one language was greater than in the other language (Table 1). The difference in extent of activation was not related to the order of the subject's acquisition of languages.

ANOVA showed no significant effect on the extent of activation (number of activated voxels) for either age of exposure to L2 (early vs late; $F_{(1,44)}<1$; NS) or language (English vs Mandarin; $F_{(1,44)}<1$; NS). There was no significant interaction between these two factors $\left(F_{(1,44)}<1\right.$; NS).

The distribution of AI in both $\mathrm{EB}$ and $\mathrm{LB}$ is comparable to data gathered for other fMRI-based Wada tests (Desmond et al., 1995; Binder et al., 1996; Lex et al., 1998), suggesting that the brains of bilinguals are no less asymmetrically organized than monolinguals.

\section{DISCUSSION}

Our findings support the hypothesis that common cortical areas are activated when fluent Mandarin-English bilinguals perform 


\begin{tabular}{|c|c|c|c|c|c|c|c|c|c|c|c|c|}
\hline & \multicolumn{2}{|c|}{ BA $22 / 21$} & \multicolumn{2}{|c|}{ BA $44 / 45$} & \multirow{2}{*}{$\frac{\text { BA37 }}{\mathrm{L}}$} & \multirow{2}{*}{$\frac{\mathrm{BA} 47}{\mathrm{~L}}$} & \multicolumn{2}{|c|}{ BA $9 / 46$} & \multicolumn{2}{|c|}{ BA 7} & \multicolumn{2}{|c|}{ BA 6} \\
\hline & $\mathrm{L}$ & $\mathrm{R}$ & $\mathrm{L}$ & $\mathrm{R}$ & & & $\mathrm{L}$ & $\mathrm{R}$ & $\mathrm{L}$ & $\mathrm{R}$ & $\mathrm{L}$ & $\mathrm{R}$ \\
\hline \multicolumn{13}{|l|}{ EB } \\
\hline TI (1) & B & B & $\mathrm{B}$ & B & B & 0 & B & 0 & B & B & B & $\mathrm{b}$ \\
\hline LE (1) & 0 & 0 & B & $\mathrm{b}$ & B & 0 & B & B & B & B & B & B \\
\hline LI (1) & BA38 & 0 & $\mathrm{~m}$ & 0 & 0 & 0 & $\mathrm{~B}$ & 0 & B & $\mathrm{b}$ & $\mathrm{m}$ & 0 \\
\hline BA (1) & B & $\mathrm{b}$ & $\mathrm{B}$ & 0 & B & B & $\mathrm{B}$ & $\mathrm{b}$ & B & B & $\mathrm{b}$ & $\mathrm{b}$ \\
\hline RE (2) & 0 & 0 & $\mathrm{~B}$ & $\mathrm{~b}$ & 0 & $\mathrm{~m}$ & $\mathrm{~B}$ & 0 & $\mathrm{~B}$ & $\mathrm{~B}$ & B & 0 \\
\hline YE (2) & 0 & 0 & $\mathrm{~B}$ & 0 & 0 & $\mathrm{~B}$ & $\mathrm{~B}$ & $\mathrm{~b}$ & $\mathrm{~B}$ & B & B & 0 \\
\hline LO (2) & B & 0 & $\mathrm{~B}$ & $\mathrm{~b}$ & B & B & $\mathrm{B}$ & 0 & $\mathrm{~B}$ & 0 & B & B \\
\hline EL (1) & 0 & 0 & $\mathrm{~B}$ & $\mathrm{e}$ & B & 0 & $\mathrm{~B}$ & 0 & B & 0 & $\mathrm{~b}$ & 0 \\
\hline LN (1) & B & 0 & $\mathrm{~B}$ & 0 & B & B & $\mathrm{B}$ & $\mathrm{b}$ & B & $\mathrm{b}$ & B & 0 \\
\hline LA (1) & 0 & 0 & $\mathrm{~B}$ & $\mathrm{e}$ & 0 & B & $\mathrm{B}$ & $\mathrm{b}$ & $\mathrm{B}$ & $\mathrm{b}$ & B & 0 \\
\hline SI (1) & 0 & 0 & $\mathrm{~B}$ & 0 & 0 & B & $\mathrm{B}$ & $\mathrm{b}$ & $\mathrm{B}$ & 0 & $\mathrm{~b}$ & 0 \\
\hline SO (1) & B & 0 & $\mathrm{~B}$ & 0 & B & $\mathrm{b}$ & $\mathrm{B}$ & $\mathrm{b}$ & $\mathrm{B}$ & B & B & $\mathrm{b}$ \\
\hline ME (2) & 0 & 0 & $\mathrm{~B}$ & 0 & B & 0 & $\mathrm{~B}$ & B & B & B & $\mathrm{b}$ & 0 \\
\hline SK (2) & BA38 & 0 & $\mathrm{~B}$ & $\mathrm{~b}$ & 0 & B & $\mathrm{B}$ & $\mathrm{b}$ & $\mathrm{B}$ & $\mathrm{B}$ & B & $\mathrm{b}$ \\
\hline JA (2) & 0 & 0 & $\mathrm{~B}$ & $\mathrm{~b}$ & 0 & $\mathrm{~b}$ & $\mathrm{~B}$ & $\mathrm{~b}$ & $\mathrm{~B}$ & $\mathrm{~B}$ & B & 0 \\
\hline \multicolumn{13}{|l|}{ LB } \\
\hline LZ (2) & 0 & 0 & $\mathrm{~b}$ & $\mathrm{~b}$ & 0 & $\mathrm{~b}$ & $\mathrm{~b}$ & $\mathrm{~b}$ & $\mathrm{~B}$ & B & $\mathrm{b}$ & $\mathrm{b}$ \\
\hline HU (2) & 0 & 0 & $\mathrm{~B}$ & $\mathrm{~b}$ & B & 0 & $\mathrm{~B}$ & $\mathrm{~b}$ & B & B & $\mathrm{B}$ & B \\
\hline YA (2) & 0 & 0 & $\mathrm{~B}$ & 0 & 0 & $\mathrm{~b}$ & $\mathrm{~B}$ & $\mathrm{~b}$ & $\mathrm{~B}$ & B & $\mathrm{b}$ & $\mathrm{b}$ \\
\hline JI (2) & 0 & 0 & $\mathrm{~B}$ & 0 & 0 & 0 & $\mathrm{~B}$ & $\mathrm{e}$ & B & $\mathrm{b}$ & 0 & 0 \\
\hline GU (2) & 0 & 0 & $\mathrm{~B}$ & $\mathrm{~b}$ & B & 0 & $\mathrm{~B}$ & $\mathrm{~b}$ & $\mathrm{~B}$ & B & $\mathrm{b}$ & $\mathrm{b}$ \\
\hline $\mathrm{ZH}(2)$ & $\mathrm{b}$ & $\mathrm{b}$ & $\mathrm{B}$ & $\mathrm{b}$ & 0 & 0 & $\mathrm{~B}$ & $\mathrm{~b}$ & B & B & $\mathrm{B}$ & $\mathrm{b}$ \\
\hline $\mathrm{ZN}(2)$ & 0 & 0 & $\mathrm{~B}$ & 0 & 0 & 0 & $\mathrm{~B}$ & B & B & B & $\mathrm{b}$ & $\mathrm{b}$ \\
\hline JU (2) & 0 & 0 & $\mathrm{~B}$ & B & 0 & 0 & $\mathrm{~B}$ & $\mathrm{~b}$ & $\mathrm{~B}$ & $\mathrm{~B}$ & B & B \\
\hline DA (2) & 0 & 0 & $\mathrm{~B}$ & 0 & 0 & 0 & $\mathrm{~B}$ & 0 & $\mathrm{~B}$ & B & $\mathrm{b}$ & 0 \\
\hline
\end{tabular}

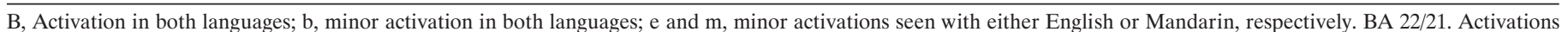

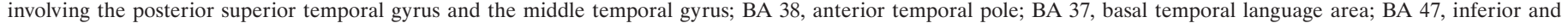
anterior portions of the inferior frontal gyrus; BA 44/45, inferior frontal gyrus; BA 9/46, dorsolateral prefrontal cortex; BA 6, premotor cortex.

cued word generation. This is true of early, as well as late, onset bilinguals. This in no way contradicts observations that differences in processing of L2 may differ according to the age of initial exposure to L2 (Weber-Fox and Neville, 1997). We emphasize the location and not the nature of word processing.

Multiple factors are postulated to determine the cortical localization of language in bilinguals (Vaid, 1983). These include tonality, direction of script, type of script, manner of L2 acquisition, stage, and age of L2 acquisition. Studies on dysphasia in Japanese suggest a difference in interhemispheric organization of ideographic and phonetic scripts (Kawamura et al., 1989). However, earlier work based on lesion, tachistoscopic, dichotic listening, or visual half-field presentation data did not directly look at the entire network of language-related areas simultaneously.

Right hemisphere involvement in processing of L2 has been suggested. However, evidence from Wada testing and electrical stimulation point to L2 representation in left hemisphere areas, similar to that seen in monolinguals (Paradis, 1997). Our data does not support a special role for the right hemisphere in the processing of single words in Mandarin. There were individuals in our study who had right frontal language activations. However, in each case, the extent to which this was so was similar for both languages.

A different brain organization for L1 and L2 in some individuals was suggested by Dehaene et al. (1997), who showed a dissociation of areas active during auditory sentence comprehension of French and English. Some subjects showed only right hemisphere activations in L2. Suggested explanations for these findings include the following: the use of different strategies for language processing in L1 and L2, an intrinsic difference in brain organization for L1 and L2 based on processing requirements, and a loss of cerebral plasticity of left hemisphere language areas when L2 is acquired later. Our results persuade us to reject the suggestion that there is a difference in brain organization between L1 and L2.

Several reasons led us to focus our attention on the prefrontal regions in the data analysis. First, these were the most robust of activations seen in the language areas and allowed for between language comparisons in all subjects. Second, this area contributed solely or heavily to the computation of asymmetry indices in noninvasive fMRI-based tests of language lateralization (Desmond et al., 1995; Binder et al., 1996). Third, differences in the cortical organization of language in early and late bilinguals were shown in the frontal (Kim et al., 1997) but not temporal (Kim et al., 1997; Perani et al., 1998) regions.

The posterior temporal region was not consistently activated with our task. At the single word level, experiments showing more (Wise et al., 1991; Demonet et al., 1992; Warburton et al., 1996) and less (Ojemann et al., 1998; Chee et al., 1999) robust posterior temporal activations have been reported. The choice of probe and control tasks (Warburton et al., 1996) are important determinants of the pattern of language activations seen. Activation of the posterior temporal area may also be modulated by syntactic difficulty, as well as frequency, of the nouns used in sentence 


\section{A Early Bilingual}
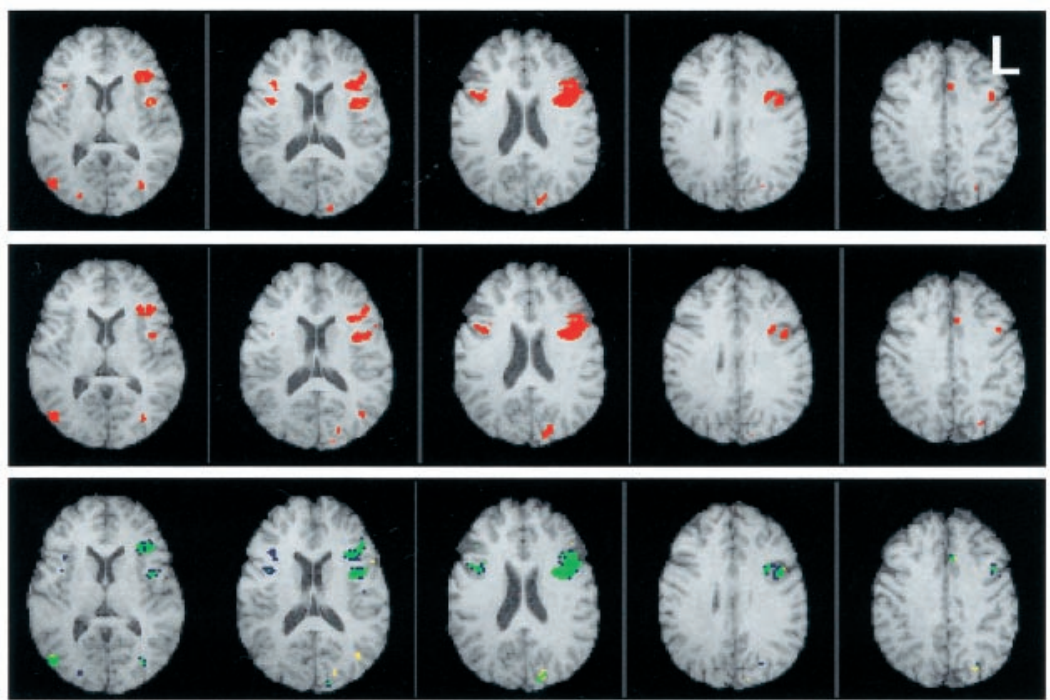

$+12 \mathrm{~mm}+18 \mathrm{~mm}+24 \mathrm{~mm}+30 \mathrm{~mm}+36 \mathrm{~mm}$

\section{B Late Bilingual}
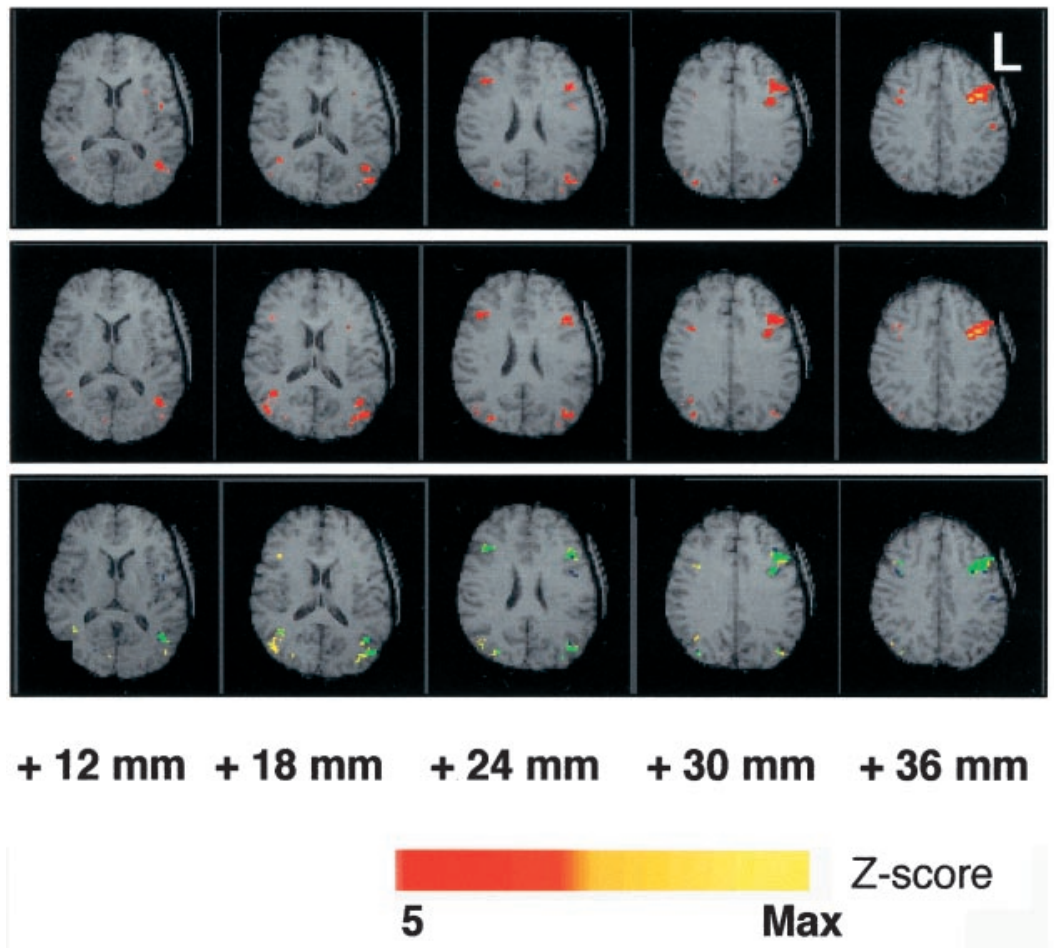

\section{English vs. Fixation}

\section{Mandarin vs. Fixation}

\author{
English \\ \& Mandarin \\ vs. Fixation
}

\section{English vs. Fixation}

\section{Mandarin vs. Fixation}

\section{English \& Mandarin vs. Fixation}

Figure 2. Maps in Talairach space show activations associated with the English and Mandarin word completion tasks compared with fixation. Data from representative early $(A)$ and late $(B)$ bilingual subjects are shown. The subject's left hemisphere is on the right of each image. The top two panels in each sequence show activations above a Z-score threshold of 5 in red and those above 10 in yellow. In the bottom panel, activations above a Z-score threshold of 5 are blue for English and yellow for Mandarin. Where there is overlap of activations, the mapped area is represented in green. The numbers below the images represent distance from the anterior commissural plane in the superior-inferior direction.

stimuli (Just et al., 1996; Keller et al., 1998). Sentence level analysis of language includes propositional and pragmatic analysis, which can be performed using different strategies. Greater parietal activation resulted from the use of a visual rather than verbal strategy in an experiment in which subjects read a sentence describing the spatial arrangement of two simple objects, examined a picture, and then indicated whether or not the picture was described by the sentence (Reichle et al., 1998). Persons less 


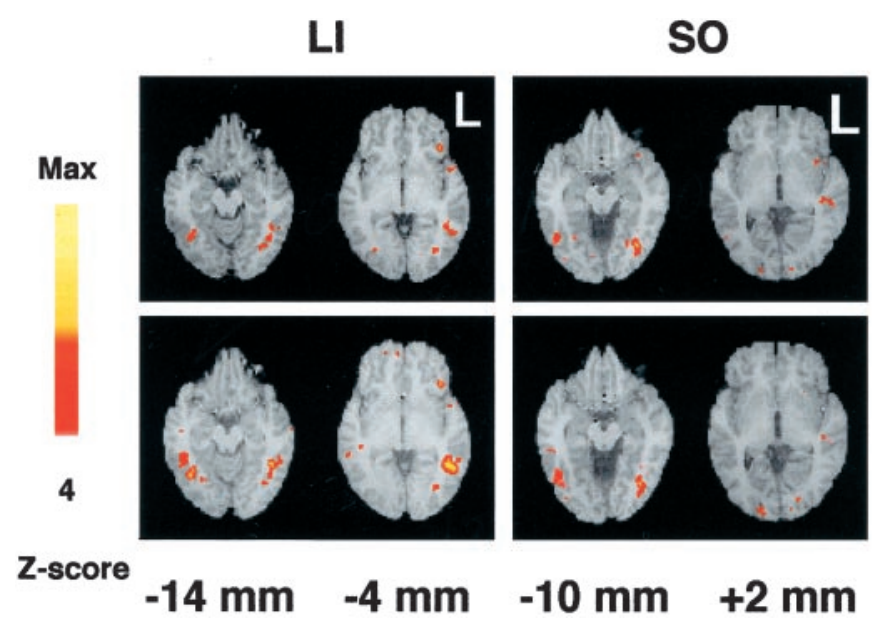

\section{Mandarin}

English

B
Figure 3. Activation maps from two representative subjects show basal temporal (BA 37), and midtemporal and posterior temporal (BA 21/22) activations with English and Mandarin word tasks. The subject's left hemisphere is on the right of each image. The numbers below the images are distances from the anterior commissural plane in the superior-inferior direction.
A Early Bilinguals

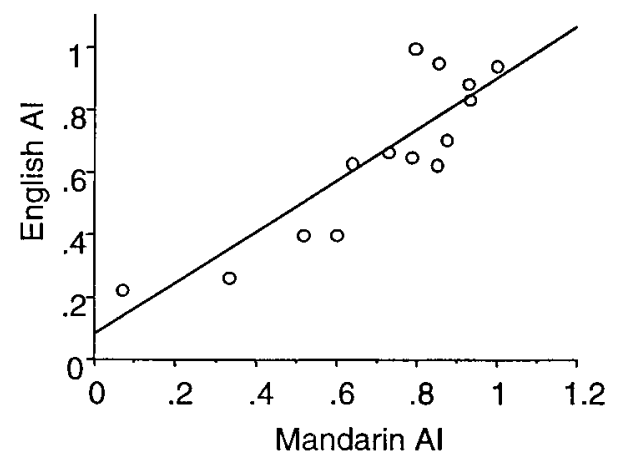

$\mathrm{Y}=.081+.819^{*} \mathrm{X} ; \mathrm{R}^{\wedge} 2=.827$

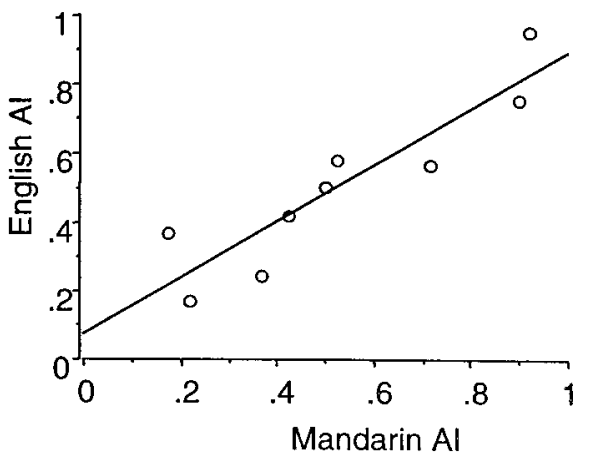

$\mathrm{Y}=.073+.827^{*} \mathrm{X} ; \mathrm{R}^{\wedge} 2=.829$
Figure 4. Correlation of the AI for English versus Mandarin in EB and LB subjects. AI $=$ Sum $(\operatorname{Voxels}(\mathrm{L}-\mathrm{R})) /$ Sum (Voxels $(\mathrm{L}+\mathrm{R})$ ). fluent in L2 may use pragmatic and metalinguistic knowledge to comprehend and generate sentences (Paradis, 1997). We postulate that differences in strategy or handling of syntactic complexity may contribute to more extensive or topographically distinct activations seen with L2 in sentence level studies.

Although there exist individuals who acquire L2 at age 16 years or later and have native or near native accuracy in L2 tasks (White and Genesee, 1996), it is generally accepted that it is easier to acquire L2 and to do so more competently if one is exposed to it earlier (Harley and Wang, 1997). Behavioral and ERP data also suggest that in Chinese-English bilinguals, some aspects of sentence anomaly detection differ according to age of initial exposure to English (Weber-Fox and Neville, 1997). However, there is no a priori reason to expect a different cortical organization of L2 to account for these differences in processing. The similarity in activations seen in early and late bilingual subjects argues against a change in cerebral plasticity for language with age in terms of where (rather than how) word processing occurs.

There are several possible reasons for the difference in our results compared with previous studies (Dehaene et al., 1997; Kim et al., 1997). Fluency in both languages has been shown recently to be an important factor in the cerebral organization of language (Perani et al., 1998). Learning English in a formal manner in school and the use of both languages in daily life in similar contexts may also favor a common organization of L1 and L2 (Vaid, 1983). The use of visually presented stimuli also obviates processing differences arising from language-specific auditory segmentation of spoken words (Mehler et al., 1994).
Our results alone should not be regarded as completely debunking the notion that L1 and L2 are organized differently. Activation of the prefrontal areas highlights higher, lexical, and generative aspects of language. In contrast, the incompletely revealed inferior temporal region is known to participate in earlier stages of word recognition (Nobre et al., 1994). The 10 cases who had fusiform gyrus activations showed overlap in activations across languages, but it is conceivable that the remaining subjects may use slightly different areas for recognition of Mandarin (ideographic) and English (alphabetic) scripts. At present, there is no clear answer to this issue; an fMRI study in which subjects were instructed to read and understand Kanji and Kana characters showed subtle differences in the location of activation of the inferior temporal cortex (Makabe et al., 1997). Visual search procedures for Mandarin and English may be script-specific (Green et al., 1996). On the other hand, Braille and English both activate common areas in BA 37, suggesting that this area is a convergence region for symbolic representations (Buchel et al., 1998). A recent magnetoencephalogram study in which subjects were presented with Kanji and Kana words (Koyama et al., 1998) also showed that the locations of equivalent current dipoles to Kanji and those to Kana did not differ at any recording site.

Given the caveats discussed, we conclude that cued word generation, even with orthographically distinct scripts, can result in the activation of common cortical areas within the left hemisphere. 


\section{REFERENCES}

Albert M, Obler L (1978) The bilingual brain: neuropsychological and neurolinguistic aspects of bilingualism. New York: Academic.

Binder JR, Swanson SJ, Hammeke TA, Morris GL, Mueller WM, Fischer M, Benbadis S, Frost JA, Rao SM, Haughton VM (1996) Determination of language dominance using functional MRI: a comparison with the WADA test. Neurology 46:978-984.

Buchel C, Price C, Friston K (1998) A multimodal language region in the ventral visual pathway. Nature 394:274-277.

Buckner RL, Raichle ME, Petersen SE (1995) Dissociation of human prefrontal cortical areas across different speech production tasks and gender groups. J Neurophysiol 74:2163-2173.

Chee M, O'Craven K, Bergida R, Rosen B, Savoy R (1999) Auditory and visual word processing studied with fMRI. Hum Brain Mapp 7:15-28.

Dehaene S, Dupoux E, Mehler J, Cohen L, Paulesu E, Perani D, van de Moortele PF, Lehericy S, Le Bihan D (1997) Anatomical variability in the cortical representation of first and second language. NeuroReport 8:3809-3815.

Demonet JF, Chollet F, Ramsay S, Cardebat D, Nespoulous JL, Wise R, Rascol A, Frackowiak R (1992) The anatomy of phonological and semantic processing in normal subjects. Brain 115:1753-1768.

Desmond JE, Sum JM, Wagner AD, Demb JB, Shear PK, Glover GH, Gabrieli JD, Morrell MJ (1995) Functional MRI measurement of language lateralization in Wada-tested patients. Brain 118:1411-1419.

Green D, Liow S, Tng S, Zielinski S (1996) Are visual search procedures adapted to the nature of the script? Br J Psychol 87:311-326.

Harley B, Wang W (1997) The critical period hypothesis: where are we now? In: Tutorials in bilingualism: psycholinguistic perspectives (de Groot A, Kroll J, eds), pp 19-51. Mahwah, NJ: Erlbaum.

Just M, Carpenter P, Keller T, Eddy W, Thulborn K (1996) Brain activation modulated by sentence comprehension. Science 274:114-116.

Kawamura M, Hirayama K, Yamamoto H (1989) Different interhemispheric transfer of kanji and kana writing evidenced by a case with left unilateral agraphia without apraxia. Brain 112:1011-1018.

Keller T, Just M, Carpenter P, Thulborn K (1998) Lexical and semantic processing in sentence comprehension. NeuroImage 7:S187.

Kim K, Relkin N, Lee K, Hirsch J (1997) Distinct cortical areas associated with native and second languages. Nature 388:171-174.

Klein D, Zatorre R, Milner B, Meyer E, Evans A (1994) Left putaminal activation when speaking a second language: evidence from PET. NeuroReport 5:2295-2297.

Klein D, Milner B, Zatorre R, Meyer E, Evans A (1995) The neural substrates underlying word generation: a bilingual functional-imaging study. Proc Natl Acad Sci USA 92:2899-2903.

Koyama S, Kakigi R, Hoshiyama M, Kitamura Y (1998) Reading of Japanese Kanji (morphograms) and Kana (syllabograms): a magnetoencephalographic study. Neuropsychologia 36:83-98.

Kuhl P (1994) Learning and representation in speech and language. Curr Opin Neurobiol 4:812-822.

Lex U, Hund M, Friederici A, von Cramon D (1998) Lateralization effects of language functions studied with fMRI. NeuroImage 7:S136.
Makabe T, Edminster WB, Jenkins BJ, Rosas HD, Kwong KK, Rosen BR, Asari S, Ohmoto T (1997) Functional MRI studies in lexical processing using Japanese Kanji and Kana characters. NeuroImage 5:S556.

Mehler J, Dupoux E, Pallier C, Dehaene-Lambertz G (1994) Crosslinguistic approaches to speech processing. Curr Opin Neurobiol 4:171-176.

Neville H, Bavelier D, Corina D, Rauschecker J, Karni A, Lalwani A, Braun A, Clark V, Jezzard P, Turner R (1998) Cerebral organization for language in deaf and hearing subjects: biological constraints and effects of experience. Proc Natl Acad Sci USA 95:922-929.

Nobre A, Allison T, McCarthy G (1994) Word recognition in the human inferior temporal lobe. Nature 372:260-263.

Ojemann GA, Whitaker HA (1978) The bilingual brain. Arch Neurol 35:409-412.

Ojemann JG, Buckner RB, Akbudak E, Snyder AZ, Ollinger JM, McKinstry RC, Rosen BR, Petersen SE, Raichle ME, Conturo TE (1998) Functional MRI studies of word-stem completion: reliability across laboratories and comparison to blood flow imaging with PET. Hum Brain Mapp 6:203-215.

Paradis M (1995) Aspects of bilingual aphasia. Oxford: Pergammon.

Paradis M (1997) The cognitive neuropsychology of bilingualism. In: Tutorials in bilingualism: psycholinguistic perspectives (de Groot A, Kroll J, eds), pp 331-354. Mahwah, NJ: Erlbaum.

Perani D, Dehaene S, Grassi F, Cohen L, Cappa S, Dupoux E, Fazio F, Mehler J (1996) Brain processing of native and foreign languages. NeuroReport 7:2439-2444.

Perani D, Paulesu E, Galles NS, Dupoux E, Dehaene S, Bettinardi V, et al (1998) The bilingual brain: proficiency and age of acquisition of the second language. Brain 121:1841-1852.

Reichle E, Carpenter P, Just M (1998) The cortical systems mediating two sentence-picture verification strategies. NeuroImage 7:S182.

Vaid J (1983) Bilingualism and brain lateralization. In: Language functions and brain organization (Segalowitz S, ed), pp 315-339. New York: Academic.

Warburton E, Wise RJ, Price CJ, Weiller C, Hadar U, Ramsay S, Frackowiak RS (1996) Noun and verb retrieval by normal subjects. Studies with PET. Brain 119:159-179.

Weber-Fox C, Neville H (1997) Maturational constraints on functional specializations for language processing: ERP and behavioral evidence in bilingual speakers. J Cognit Neurosci 8:231-256.

White L, Genesee F (1996) How native is near-native? The issue of ultimate attainment in adult second language acquisition. Second Lang Res 12:233-265.

Wise R, Chollet F, Hadar U, Friston K, Hoffner E, Frackowiak R (1991) Distribution of cortical neural networks involved in word comprehension and word retrieval. Brain 114:1803-1817.

Woods RP, Cherry SR, Mazziotta JC (1992) Rapid automated algorithm for aligning and reslicing PET images. J Comput Assisted Tomogr 16:620-633. 